\title{
Powder Casting: Producing Bulk Metal Components from Powder Without Compaction
}

\author{
JAMES D. PARAMORE (iD, ${ }^{1,2,3}$ MATTHEW K. DUNSTAN ${ }^{10},{ }^{1,4}$ \\ BRADY G. BUTLER (10, ${ }^{1,2,5}$ and DANIEL O. LEWIS (1) ${ }^{1,6}$
}

1.-United States Army Research Laboratory, 575 Ross St (3003 TAMU), College Station, TX 77843-3003, USA. 2.-Department of Materials Science and Engineering, Texas A\&M University, 575 Ross St (3003 TAMU), College Station, TX 778433003, USA. 3.-e-mail: james.d.paramore.civ@mail.mil. 4.—e-mail: matthew.k.dunstan.civ@ mail.mil. 5.—e-mail: brady.g.butler.civ@mail.mil.6.—e-mail: danlewis2595@tamu.edu

Powder casting was developed to produce metal components with near-theoretical density from low-cost, loose powder using hydrogen sintering and phase transformation. This has significant implications for non-beam metal additive manufacturing processes (e.g., metal extrusion AM, binder jetting, and ordered powder lithography), which produce green parts with relatively low densities. Additionally, powder casting can enable the production of geometries typically not suitable for powder processing, such as plate and bar stock. In the current study, Ti-6Al-4V, $\mathrm{Zr}$, and $\mathrm{Hf}$ were densified to $99.2 \%$, $95.7 \%$, and $94.0 \%$ of their respective theoretical densities, when sintered from loose powder at $1200^{\circ} \mathrm{C}$ for $4 \mathrm{~h}$. The relative density and pore size distributions of Ti-6Al-4V produced by powder casting were very similar to those produced by press-and-sinter HSPT. The powder-cast Ti-6Al-4V samples also displayed ductility consistent with press-and-sinter HSPT. However, they exhibited lower strength due to unintentional overheating during the dehydrogenation step.

\section{INTRODUCTION}

While hydrogen is detrimental to the mechanical properties of finished components, the presence of hydrogen during powder metallurgy (PM) processing has several benefits, including its ability to improve densification. ${ }^{1-4}$ Additionally, when hydrogen is added to titanium, it enables new phase transformations that allow for microstructural engineering without requiring mechanical working., Introducing hydrogen in the form of $\mathrm{TiH}_{2}$-containing feedstocks has been used for over 50 years in PM. ${ }^{6-8}$ However, similar results are obtained by using a $\mathrm{H}_{2}$-containing atmosphere, instead of vacuum or inert gas, to sinter elemental Ti powders. ${ }^{9-11}$

Over the last decade, the authors and their collaborators have developed a process named hydrogen sintering and phase transformation (HSPT), a blended elemental press-and-sinter PM process. ${ }^{12-14}$ This process was developed to produce high-performance titanium alloys with wrought-like microstructures and properties using only low-cost feedstocks and processing. To date, this process has been reported to produce tensile strength exceeding $1 \mathrm{GPa}$, ductility exceeding $20 \% \mathrm{EL}$ and $45 \% \mathrm{RA}$, and fatigue endurance limits of $50-60 \%$ of the ultimate tensile strength. ${ }^{14}$

Due to the excellent densification of titanium alloys during hydrogen sintering, it was hypothesized in the current study that near-full-density (>99\%) structural components could be sintered directly from loose powder. Loose powder sintering is a common approach to produce intentionally porous metals. ${ }^{15}$ However, if full density is desired, one of several methods is typically necessary to produce full-density components from metal powder. ${ }^{16}$ Compaction can be used before sintering, during sintering (i.e., pressure-assisted sintering, such as hot pressing), or after sintering (e.g., hot isostatic pressing) to close pores. Additionally, relatively expensive spherical powders with excellent flowability and engineered particle size distributions can be used to maximize loose packing and improve green density. Finally, infiltration of 
another molten metal can be used to fill open porosity left by sintering. However, the goal of the current work was to achieve near-theoretical density from low-cost, non-spherical powders without requiring compaction or infiltration.

Recently, metal additive manufacturing (AM) processes that do not require a high-energy beam (e.g., binder jetting, ${ }^{17}$ metal extrusion AM, ${ }^{18}$ and ordered powder lithography ${ }^{19}$ ) are gaining attention, which can leverage decades of experience in $\mathrm{PM}$ to produce more predictable and controllable microstructures. These AM processes produce "green parts" (shaped powder parts before sintering), which are subsequently debound and sintered via more predictable and homogenous heating than beam-based technologies. However, the green parts produced tend to have a large degree of porosity and/or a large volume fraction of binder. Therefore, producing structural components with these processes requires achieving near-theoretical density from a low starting density.

Currently, the authors are primarily interested in improving non-beam AM via hydrogen sintering. However, the original motivation for this work was the ability to produce large, simple geometries not typically suitable for powder processing, such as plate and bar stock. Therefore, the process was named "powder casting" due to its similarity to melt casting. That is, the material is poured into a mold and sintered as loose powder to produce a bulk metal component.

\section{EXPERIMENTAL METHODS}

The titanium powder used in this study was received as commercially pure $\mathrm{TiH}_{2}$ with a 250$841 \mu \mathrm{m}(-20+60 \mathrm{mesh})$ particle size range. This material was supplied as the intermediate product of a commercial hydride-dehydride (HDH) process. $^{20}$ The as-received powder was ball milled in 250-g batches in an Ar atmosphere. The grinding medium was $6.35-\mathrm{mm}$ stainless steel (440C) balls in a 10:1 ball:powder ratio by weight. The milling jar was made of 304 stainless steel ( $97.2 \mathrm{~mm}$ internal diameter by $142.9 \mathrm{~mm}$ internal length). Milling was done at $64.7 \mathrm{rpm}(47.7 \%$ critical speed) for $30 \mathrm{~min}$. After milling, the powder was sieved to $<37 \mu \mathrm{m}$ ( -400 mesh) on a vibratory sieve shaker with an ultrasonic agitator (HK Technologies HK-8). The sieved powder was blended with as-received $<44 \mu \mathrm{m} \quad(-325$ mesh $)$ master alloy (60 wt.\% aluminum and $40 \mathrm{wt} . \%$ vanadium). These powders were mixed for $1 \mathrm{~h}$ in a 1-L bottle on a tumbling shaker-mixer (Glenn Mills T2C). The blended powder contained 9.6 wt.\% master alloy (balance $\mathrm{TiH}_{2}$ ), which produced Ti-6Al-4V after hydrogen was removed. Both the $\mathrm{TiH}_{2}$ and master alloy powders were received from Reading Alloys (AMETEK) and had reported purities of $>99.8$ wt.\% $(\sim 0.13$ wt.\% $\mathrm{O}, \sim 0.02$ wt.\% $\mathrm{C}$, and $\sim 0.005$ wt.\% Fe).
The zirconium used in this study was purchased from Alfa Aesar as $<44 \mu \mathrm{m}$ ( -325 mesh) zirconium hydride $\left(\mathrm{ZrH}_{2}\right)$ powder with $>99.7$ wt.\% purity. The hafnium used in this study was also purchased from Alfa Aesar as $<44 \mu \mathrm{m} \quad(-325$ mesh) hafnium metal powder, which was produced by the HDH process. This powder was reported to contain 2-3.5 wt.\% zirconium, and to have a purity of $>99.7$ wt.\% (excluding zirconium content). Both powders were used in the as-received condition.

The tap density of each powder was obtained by following the ASTM B527 standard ${ }^{21}$ and using a machine specifically built for this purpose (Quantachrome Autotap). It was determined that roughly 1000-2000 taps were necessary to achieve the tap density of each powder.

The casting molds used for the Ti-6Al-4V samples were alumina crucibles $(\sim 25.4 \mathrm{~mm}$ internal diameter by $\sim 100 \mathrm{~mm}$ internal height), which were filled with $\sim 60 \mathrm{~g}$ of loose powder before tapping. Examples of the alumina crucibles used in this study are shown in Fig. 1. To account for possible variations between experiments, each sample was tapped 3000 times to ensure tap density was reached.

The zirconium and hafnium samples were sintered in custom molybdenum crucibles made from foil ( $\sim 12 \mathrm{~mm}$ diameter by $\sim 2 \mathrm{~mm}$ height), which were filled with either $\sim 0.6 \mathrm{~g}$ of $\mathrm{ZrH}_{2}$ or $\sim 1 \mathrm{~g}$ of Hf. Due to the unfeasibility of using these crucibles on the tapping machine, they were manually tapped on a benchtop.

Sintering was performed in a furnace capable of running inert gas, hydrogen/inert gas mixtures, or vacuum atmospheres (Thermal Technologies Astro 1000). A schematic representation of the thermal profile and atmospheres used during the entire sintering and dehydrogenation process are shown in Fig. 2. This sintering profile is a modification of the HSPT profile that has been previously detailed in the literature. ${ }^{12,14}$ Because two of the feedstocks used in this study contained hydrides, a much slower ramp rate was added to the beginning of the typical HSPT profile. Otherwise, dehydrogenation

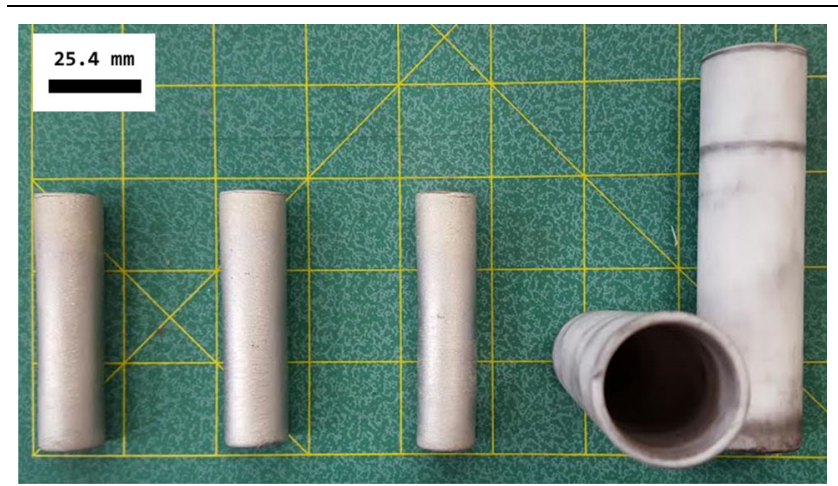

Fig. 1. As-sintered Ti-6Al-4V samples produced by powder casting and the alumina molds that were used. 


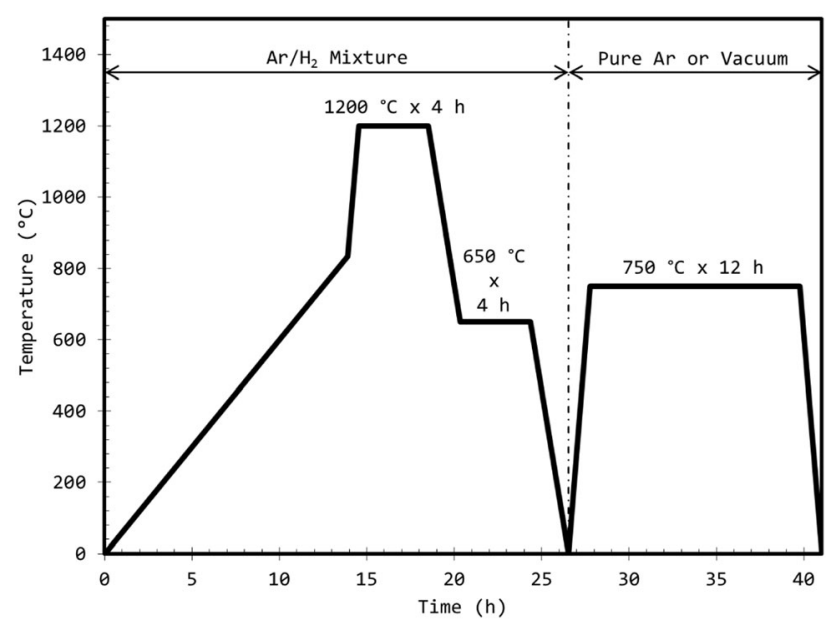

Fig. 2. Nominal thermal profile and atmospheres used to sinter powder-cast samples.

of the materials during heating would cause a rapid release of $\mathrm{H}_{2}$ gas, thereby agitating the loose powder and producing defects.

The first two sintering steps used in this study were performed under a $50 \% \mathrm{H}_{2}$ atmosphere (balance $\mathrm{Ar}$ ). The $\mathrm{H}_{2}$ partial pressure was produced by flowing $1 \mathrm{~L} / \mathrm{min}$ of $\mathrm{H}_{2}$ and $1 \mathrm{~L} / \mathrm{min}$ of $\mathrm{Ar}$ at atmospheric pressure using electronic mass flow controllers (Aalborg GFC). The samples were first heated to $835^{\circ} \mathrm{C}$ at $1^{\circ} \mathrm{C} / \mathrm{min}$, then immediately heated to $1200^{\circ} \mathrm{C}$ at $10^{\circ} \mathrm{C} / \mathrm{min}$, and held at that temperature for $4 \mathrm{~h}$ to allow for densification. After densification, the samples were cooled to $650^{\circ} \mathrm{C}$ at $5^{\circ} \mathrm{C} / \mathrm{min}$ and held there for $4 \mathrm{~h}$. The purpose of this step was to allow grain refinement due to phase transformations in the (Ti-6Al-4V)-H system. After the phase transformation step, the samples were furnace-cooled to room temperature.

The final step was done under high vacuum $\left(<1.3 \times 10^{-3} \mathrm{~Pa}\right)$ to allow for dehydrogenation of the material. Dehydrogenation thermodynamics and kinetics are controlled by hydrogen partial pressure rather than absolute system pressure. Therefore, inert gas atmospheres can also be used. However, it is typically more convenient and cost effective to use a vacuum atmosphere in a laboratory setting. During this step, it was intended to heat the samples to $750^{\circ} \mathrm{C}$ at $10^{\circ} \mathrm{C} / \mathrm{min}$, hold there for $12 \mathrm{~h}$, and furnace-cool to room temperature. However, the authors believe the actual dehydrogenation temperature was between $800^{\circ} \mathrm{C}$ and $850^{\circ} \mathrm{C}$ due to an issue with thermocouple placement in the furnace.

The press-and-sinter Ti-6Al-4V green parts were prepared by loading $\sim 60 \mathrm{~g}$ of the Ti-6Al-4V feedstock into latex bags (19 $\mathrm{mm}$ diameter by $114 \mathrm{~mm}$ length; Trexler Rubber). The bags were then evacuated of air, and compacted in a cold isostatic press
(American Isostatic Presses CP360) at $350 \mathrm{MPa}$ for $7 \mathrm{~min}$. These samples were sintered using the same HSPT profile as the power-cast samples, but without the initial slow ramp to $835^{\circ} \mathrm{C}$.

The density of every sintered sample was measured via the Archimedes method. ${ }^{22}$ This was done by measuring the weight of each sample when dry and when submerged in deionized water using a balance with $0.1-\mathrm{mg}$ resolution. The temperature of the water was measured with a thermocouple. The difference in measured weights when the sample was dry and when it was submerged was then divided by the temperature-dependent density of water to determine the precise volume of each sample.

A cross-section of each Ti-6Al-4V sample was taken at a distance of at least one diameter from the end of the as-sintered cylinders using a high-speed sectioning saw (ATM Brillant 220). These crosssections were then ground with ANSI 180-grit SiC paper, followed by 320-grit $\mathrm{SiC}$ paper. After grinding, the samples were polished using $9-\mu \mathrm{m}$ followed by $3-\mu \mathrm{m}$ diamond suspension in oil. The samples were then "attack polished" for 5 min using 3 parts of $0.04-\mu \mathrm{m}$ colloidal silica in water mixed with 1 part of $30 \% \mathrm{H}_{2} \mathrm{O}_{2}$. Micrographs were acquired from the polished surfaces with a scanning electron microscope (SEM; Phenom XL) using a backscattered electron detector, 6-mm working distance, and a 15$\mathrm{kV}$ accelerating potential.

The pore size distribution of the powder-cast $\mathrm{Ti}$ $6 \mathrm{Al}-4 \mathrm{~V}$ samples was calculated from 16 randomly selected low-magnification SEM images (each containing a field of view larger than $500 \mu \mathrm{m} \times 500$ $\mu \mathrm{m})$. Automated image analysis was performed using the Fiji distribution of ImageJ. ${ }^{23}$ The noise in each image was first reduced via two iterations of Kuwahara filtering with a window size of 11 pixels $(\sim 2.87 \mu \mathrm{m})$. A threshold was then applied to produce a binary image, thereby eliminating all features that were not pores. Finally, the "Analyze Particles" command was used to generate a dataset of size and shape for every pore in the micrographs. The diameter of each pore was taken as the largest Feret diameter measured by ImageJ. Therefore, the reported diameter was that of the largest dimension of the pore cross-section.

After the metallographic cross-sections had been removed, the samples were machined into round tensile bars with a gauge diameter of $6.35 \mathrm{~mm}$ and a gauge length of $25.4 \mathrm{~mm}$, following ASTM E8 specifications. $^{24}$ Digital image correlation (DIC) was used to measure strain during the tensile tests, ${ }^{25}$ using Vic3D software. To produce highcontrast features to track with DIC, each tensile bar was air-brushed with fine black speckles on a white background. The samples were tested at a strain rate of $3 \times 10^{-4} \mathrm{~s}^{-1}$. 


\section{RESULTS}

The Ti-6Al-4V samples picked up about 0.1 wt.\% (1000 ppmw) of oxygen during milling and sintering, resulting in the final parts having $\sim 0.23 \mathrm{wt} . \%$ O. Interestingly, analysis of the as-milled powder typically reports $\sim 0.05 \mathrm{wt} . \%$ (500 ppmw) more oxygen than the sintered material. The authors assume that this is due, at least in part, to the presence of adsorbed air on the large surface area of the milled powder, which is desorbed during sintering as hydrogen is evolved from the $\mathrm{TiH}_{2}$ powder. It has been previously determined that there is negligible iron pickup $(<0.005$ wt.\%) from the jar and media during milling, ${ }^{26}$ owing to the low energy and short times required to sufficiently mill $\mathrm{TiH}_{2}$.

The average density of all samples produced in this study are shown in Fig. 3. For comparison, the average density of Ti-6Al-4V produced by press-andsinter HSPT is also shown, as reported in the literature. ${ }^{14,27-30}$ Despite using no compaction, powder casting produced a relative density of $>99 \%$ for Ti-6Al-4V, similar to press-and-sinter.

The melting points of Ti-6Al-4V $\left(1660^{\circ} \mathrm{C}\right.$ liquidus $)$, $\mathrm{Zr}\left(1855^{\circ} \mathrm{C}\right)$, and $\mathrm{Hf}\left(2233^{\circ} \mathrm{C}\right)$ are also shown in Fig. 3. Sintering is a diffusional process, so densification is typically dependent on the homologous temperature during sintering. Therefore, $\mathrm{Zr}$ was sintered to an average density of $95.7 \%$ and $\mathrm{Hf}$ to $94.0 \%$. Both of these values were indicative of the final stage of sintering being reached ( $>92 \%)$, and correspond to the elimination of open porosity networks. ${ }^{16}$

The microstructures of the Ti-6Al-4V produced by powder casting are shown in the low- and highmagnification micrographs in Fig. 4(a) and (b), respectively. Additionally, the typical microstructure of Ti-6Al-4V produced by the press-and-sinter HSPT process (350 MPa compaction pressure) are shown in the low- and high-magnification

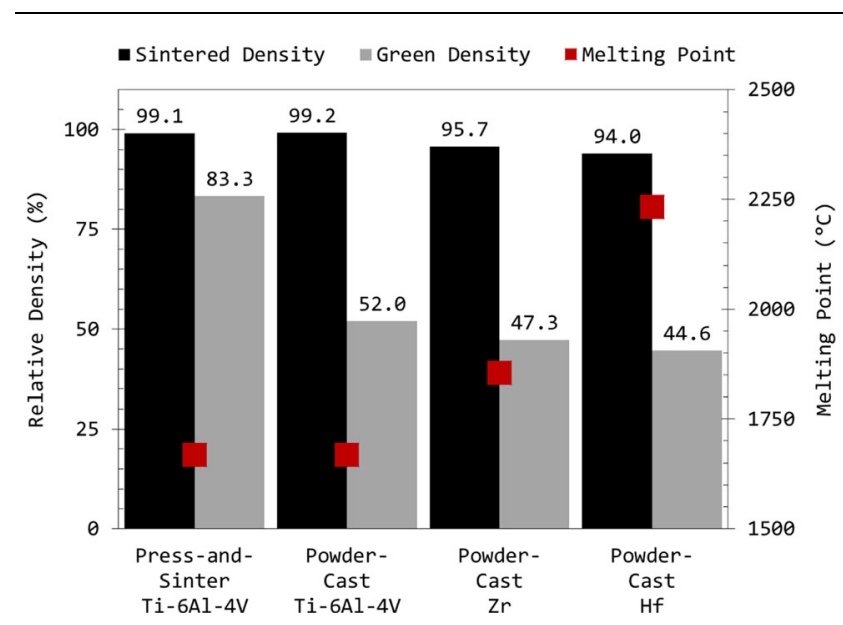

Fig. 3. The average relative green and sintered density of each powder-cast condition, the average relative green and sintered density of Ti-6Al-4V produced by press-and-sinter HSPT from the literature, ${ }^{14,27-30}$ and the melting points of the three metals. micrographs of Fig. 4c and d, respectively. A cursory analysis of these micrographs indicates that the powder-cast Ti-6Al-4V has a pore size/shape distribution similar to that of the press-and-sinter material, which will be further discussed below.

The most obvious difference between the conditions in Fig. 4 is the grain size and morphology. The HSPT process has been previously shown ${ }^{12-14,27}$ to produce an ultrafine-grained lamellar microstructure. This is due to unique phase transformations in the (Ti-6Al-4V)-H system. Figure 4(a) and (b) clearly do not show an ultrafine-grained microstructure. However, this disparity is not inherently due to the unique processing conditions used in powder casting (i.e., lack of compaction and the slow initial ramp rate). Such a microstructure has been previously documented by the authors to result from an excessive dehydrogenation temperature (i.e., 800$\left.850^{\circ} \mathrm{C}\right) .{ }^{31}$ Unintentional overheating during dehydrogenation in the specific furnace used in this study has been previously experienced by the authors, resulting from the thermocouple not being properly arranged in the hot zone. As such, the observed difference in microstructural evolution was due to equipment/experimental error, and not to the process itself.

It should be noted that the authors believe overheating did not occur during the $\mathrm{H}_{2}$ sintering step in this study. A non-negligible temperature disparity has been previously confirmed to only occur in this furnace under vacuum and at moderate temperatures $\left(<1000^{\circ} \mathrm{C}\right)$. It is assumed this is due to the lack of thermal conductivity in vacuum versus $\mathrm{H}_{2}$ atmospheres and lower thermal radiation at lower temperatures, both of which exacerbate the temperature gradient. Confirmation of this was obtained from the resulting microstructure. The sintering temperature determines the size of the prior $\beta$ grains, ${ }^{29}$ which was consistent with $1200^{\circ} \mathrm{C}$ sintering in this study.

Figure 5 shows the distribution of pore size (by frequency) of powder-cast Ti-6Al-4V. The cumulative distribution is shown as the red line on the same plot. Additionally, a representative processed micrograph of this material is shown, which has been processed as described in the Experimental Methods section. The black spots on this micrograph correspond to pores.

The average pore diameters in each micrograph were close to the overall average, ranging between $7.5 \mu \mathrm{m}$ and $10.2 \mu \mathrm{m}$ among the 16 micrographs versus the overall average of $8.5 \mu \mathrm{m}$. Finally, the area fraction of pores in all micrographs calculated by ImageJ was $1 \%$, which is close to the volume fraction of pores measured by the Archimedes method. The measured area fraction in a crosssectional image and volume fraction of pores should be equal if the pores are randomly distributed. ${ }^{32}$ As such, the $4-\mathrm{mm}^{2}$ area appears to be a reasonably representative sample size for pore analysis. In addition to having a high relative density (>99\%), 

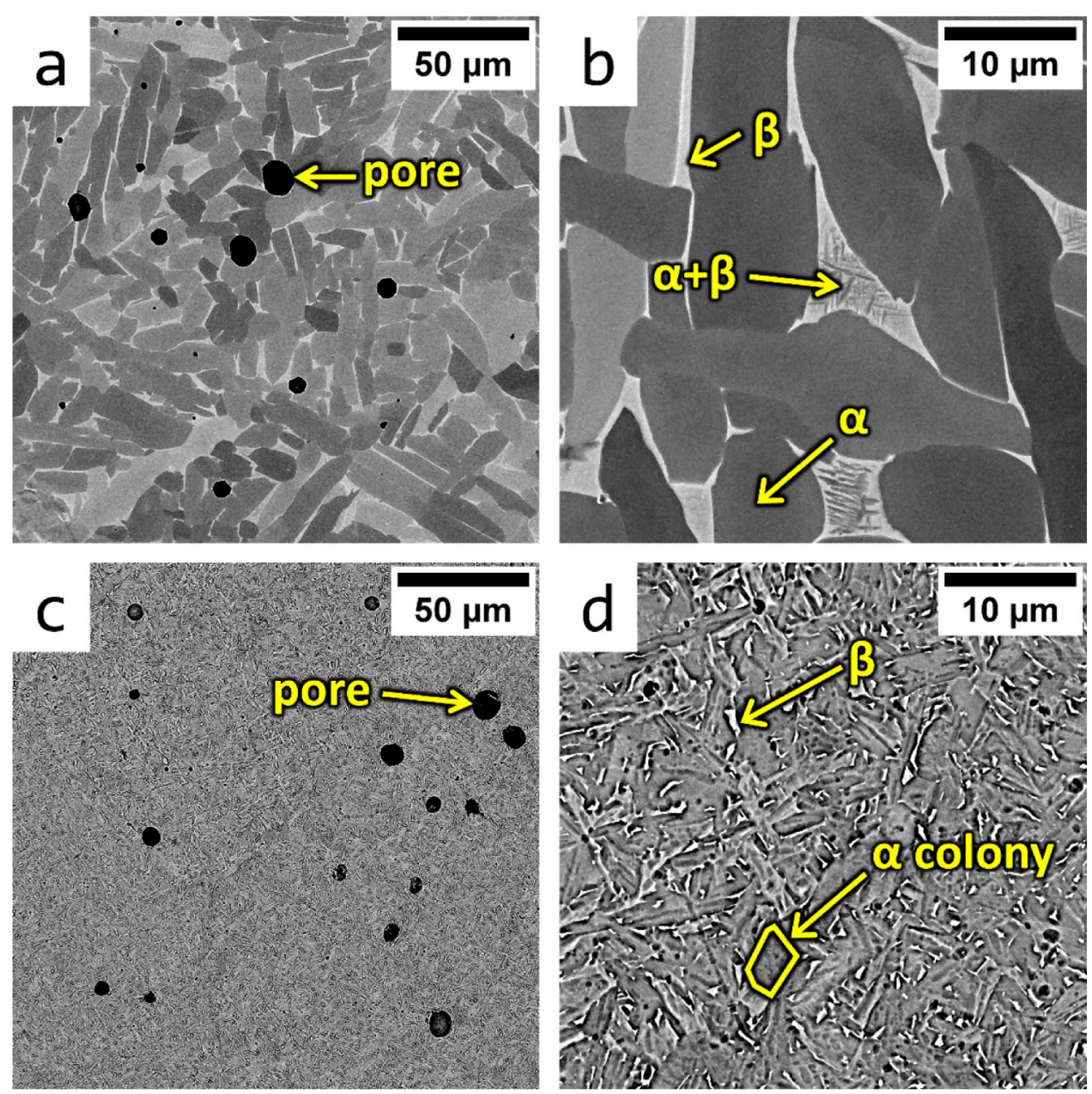

Fig. 4. Microstructures produced by the HSPT process: (a) low and (b) high magnification of powder-cast Ti-6Al-4V; (c) low and (d) high magnification of press-and-sinter Ti-6Al-4V. The stark difference in grain size and morphology was due to experimental error during dehydrogenation of the powder-cast samples.
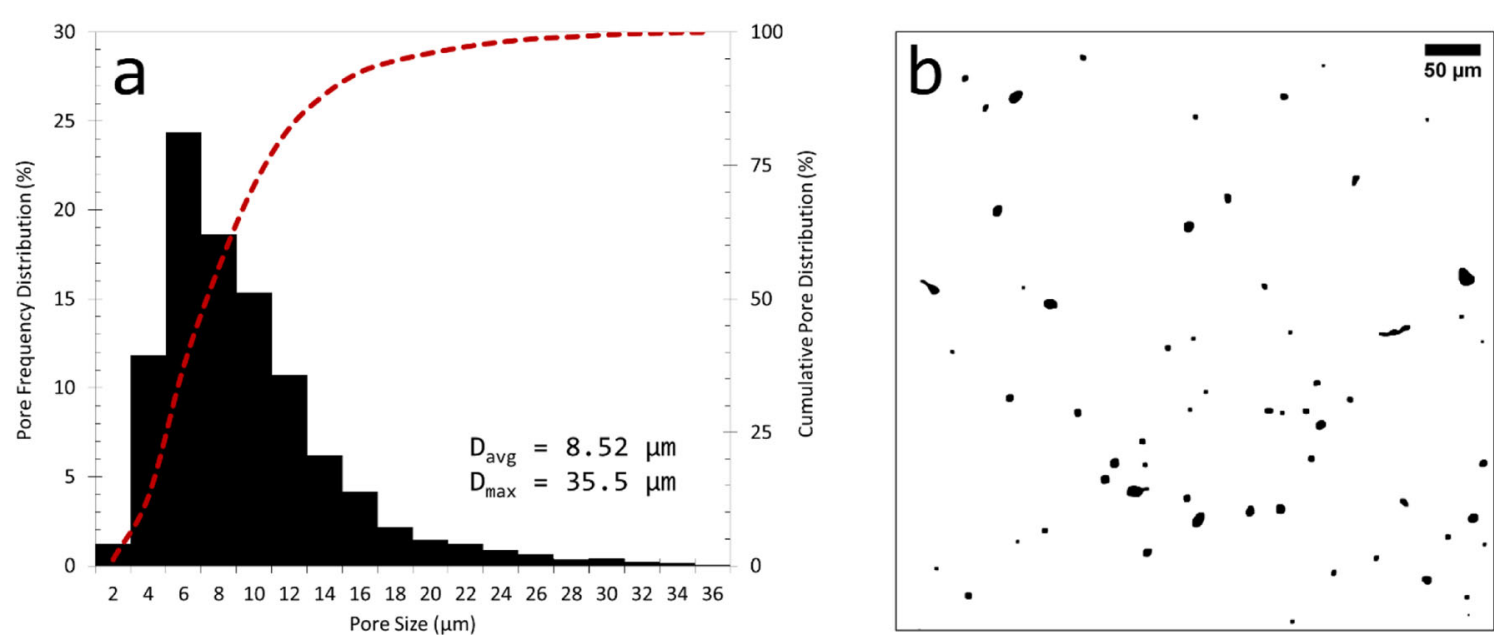

Fig. 5. (a) Frequency and cumulative pore size distribution calculated from 16 random and unique SEM micrographs of Ti-6Al-4V produced by powder casting, and (b) an example of a processed micrograph used to measure and count pores.

the powder-cast Ti-6Al-4V also had small average $\left(D_{\text {avg }}=8.5 \mu \mathrm{m}\right)$ and maximum $\left(D_{\max }=35.5 \mu \mathrm{m}\right)$ pore sizes.
Engineering stress-strain curves produced in this study are shown in Fig. 6. Additionally, average values of tensile properties and densities are shown 
in Table I for both powder-cast material from this study and press-and-sinter material from previous work. Due to the fact that there was a clear outlier among the three powder-cast tensile bars, these data are presented both with and without this data point. Finally, the ASTM B348 specifications $^{33}$ for annealed grade $5 \mathrm{Ti}-6 \mathrm{Al}-4 \mathrm{~V}$ are given for reference.

From the mechanical data, it can be seen that powder-cast Ti-6Al-4V is capable of achieving ductility and tensile strength beyond the minimums specified by the ASTM standard for annealed Grade 5 wrought Ti-6Al-4V. However, the tensile strength and toughness values are quite a bit lower than would be expected from the HSPT process. Since

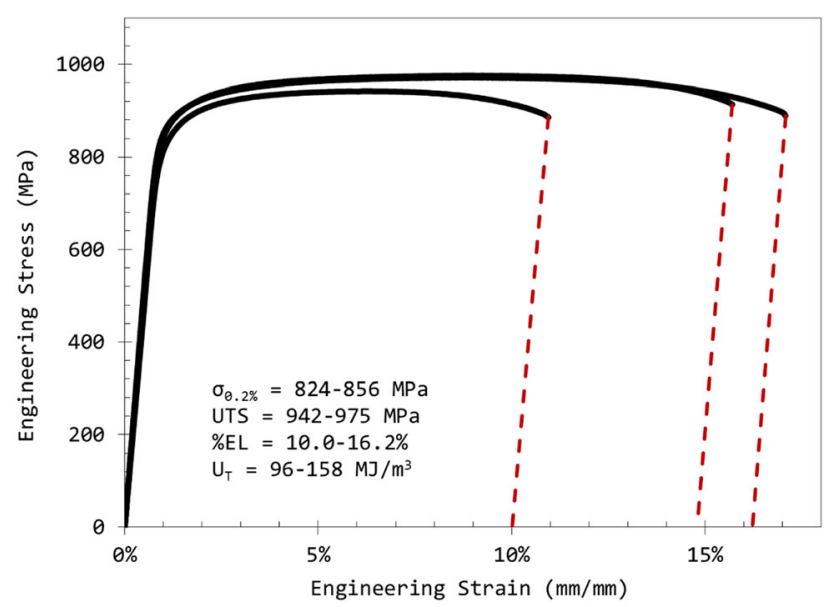

Fig. 6. Engineering stress-strain curves for powder-cast Ti-6Al-4V and the ranges of properties measured. $\sigma_{0.2 \%}$ yield strength, UTS ultimate tensile strength, \%EL plastic elongation at fracture, $U_{T}$ toughness measured as the area under the stress-strain curves. powder casting clearly produces densities and pore size distributions consistent with those of prior press-and-sinter HSPT studies, it is most likely that the underperformance in strength was due to the relatively coarse microstructure produced by the unintentionally high dehydrogenation temperature.

\section{DISCUSSION}

The most interesting finding in this study was the excellent densification behavior of Ti-6Al-4V from loose powder. The reader is referred to the works of German for detailed information on mechanisms of sintering. ${ }^{16}$ Based on these mechanisms, densification during pressureless sintering can be improved by the following strategies:

1. Increasing interparticle contact in the green part

2. Increasing self-diffusion of the metal

3. Minimizing insoluble gas trapped inside pores

This first strategy is commonly achieved through compaction or using powder with excellent loose packing. Neither of these methods are used in powder casting, so the current results must be due to strategies 2 and 3 .

The second strategy requires modification of titanium self-diffusivity, which benefits all stages of sintering. Hydrogen has long been used as a temporary alloying element to improve the hotworkability of titanium. ${ }^{34}$ This is explained by improved self-diffusion of titanium in the presence of hydrogen, ${ }^{35}$ which itself can be explained by two different mechanisms. The self-diffusivity of $\beta$ titanium is reported to be three orders of magnitude higher than that of $\alpha$ titanium at the $\beta$-transus temperature. ${ }^{36}$ Hydrogen is a very strong $\beta$

Table I. Powder-cast and press-and-sinter Ti-6Al-4V properties and ASTM B348 minimums

\begin{tabular}{|c|c|c|c|c|c|c|}
\hline Condition & Details & Refs & $\begin{array}{l}\sigma_{\mathbf{0 . 2}} \% \\
(\mathrm{MPa})\end{array}$ & $\begin{array}{l}\text { UTS } \\
(\mathrm{MPa})\end{array}$ & $\% \mathbf{~}{ }_{(\%)}$ & $\underset{(\%)}{\rho_{\mathbf{r}}}$ \\
\hline $\begin{array}{l}\text { Press-and- } \\
\text { Sinter }\end{array}$ & $\begin{array}{l}350 \mathrm{MPa} \text { cold isostatic compaction, } \\
\text { standard HSPT sintering profile, } \\
\text { ultrafine-grained lamellar } \alpha \text { grains }\end{array}$ & $14,27-30$ & $963 \pm 7$ & $1018 \pm 5$ & $14.2 \pm 1.1$ & $99.1 \pm 0.1$ \\
\hline $\begin{array}{l}\text { Press-and- } \\
\text { Sinter }\end{array}$ & $\begin{array}{l}350 \mathrm{MPa} \text { cold isostatic compaction, } \\
\text { HSPT sintering profile plus additional } \\
\text { heat treatment, globular } \alpha \text { grains }\end{array}$ & 27,28 & $876 \pm 4$ & $950 \pm 1$ & $18.4 \pm 0.8$ & $99.1 \pm 0.1$ \\
\hline $\begin{array}{l}\text { Powder-Cast } \\
\text { All Data }\end{array}$ & $\begin{array}{l}\text { No compaction, HSPT sintering } \\
\text { profile with over-temp on } \\
\text { dehydrogenation, globular } \alpha \text { grains }\end{array}$ & This study & $844 \pm 10$ & $963 \pm 10$ & $13.7 \pm 1.8$ & $99.2 \pm 0.1$ \\
\hline $\begin{array}{l}\text { Powder-Cast } \\
\text { Outlier } \\
\text { Omitted }\end{array}$ & $\begin{array}{l}\text { No compaction, HSPT sintering } \\
\text { profile with over-temp on } \\
\text { dehydrogenation, globular } \alpha \text { grains }\end{array}$ & This study & $853 \pm 3$ & $973 \pm 2$ & $15.5 \pm 0.7$ & $99.1 \pm 0.1$ \\
\hline $\begin{array}{c}\text { ASTM B348 } \\
\text { Minimums }\end{array}$ & & 33 & 828 & 895 & 10.0 & - \\
\hline
\end{tabular}


stabilizer and significantly decreases the $\beta$-transus temperature, ${ }^{37}$ thereby allowing formation of the $\beta$ phase at lower temperatures. Additionally, increases in the self-diffusivity of titanium via the formation of hydrogen-induced defects have been shown. From first principles calculations, Han et al. ${ }^{38}$ showed that the activation energy for self-diffusion of $\alpha$ titanium is reduced by the presence of hydrogen, due to lower vacancy formation and migration energies. Unfortunately, the study did not consider diffusion in the $\beta$ phase. However, experimental studies by Laptev et al. ${ }^{39}$ determined that titanium defects consisting of both vacancies and hydrogen-vacancy complexes increased in number with increasing hydrogen concentration in both the $\alpha$ and $\beta$ phases. Increased hydrogen-induced defect concentrations and the relationship to increased self-diffusivity has been discussed in the literature for several other transition metals, including $\mathrm{Ni}, \mathrm{Pd}, \mathrm{Cr}$, and $\mathrm{Nb}{ }^{40,41}$ Therefore, it is clear that hydrogen increases selfdiffusion in several metals, including titanium alloys.

The third strategy for improving densification requires that the material is either evacuated of gas (e.g., vacuum sintering), or contains gasses with appreciable solubility and high mobility in the metal. Hydrogen is known to have $>10$ at.\% solubility in $\beta$ titanium at $1200^{\circ} \mathrm{C}$. Furthermore, hydrogen, being a very small interstitial, diffuses rapidly in titanium alloys at this temperature. ${ }^{42,43}$ As such, hydrogen can escape from enclosed pores with relative ease via diffusion. The sintering atmosphere used during HSPT contains Ar. However, the $\mathrm{TiH}_{2}$ feedstock decomposes into $\beta$ titanium at elevated temperatures, and the solubility of hydrogen in the $\beta$ phase decreases with further increases in temperature. ${ }^{44}$ Therefore, as the material is heated, the voids between the powder particles are continually purged by a release of $\mathrm{H}_{2}$ gas. Furthermore, dilatometry studies have shown that the majority of densification during the HSPT process occurs during heating. ${ }^{45}$ This demonstrates that much of the pore network has closed before $\mathrm{H}_{2}$ stops being released from the sample, meaning that the pores are predominantly filled with the soluble gas during the final stages of sintering.

Despite the fact that aluminum has a low melting point, it is assumed that the liquid phase did not form during sintering of the Ti-6Al-4V samples. Each particle in the $\mathrm{Al} / \mathrm{V}$ master alloy powder had a nominal vanadium composition slightly higher than the $\mathrm{Al}_{3} \mathrm{~V}$ intermetallic. From the phase diagram, $\mathrm{Al}_{3} \mathrm{~V}$ has a peritectic at $\sim 1250^{\circ} \mathrm{C}$, and the temperature at which liquid forms increases with further vanadium content. ${ }^{46}$ Additionally, when used to produce Ti-6Al-4V, aluminum diffuses from the master alloy particles more readily than vanadium, and even begins to diffuse well below the sintering temperature during heating. ${ }^{47}$ For this reason, it would be unlikely for aluminum to concentrate and form lower-melting-point regions within the samples.

The homogenization of alloying elements is another primary concern for sintering Ti-6Al-4V from blended powders. Even when pressure-assisted sintering (e.g., hot pressing) is used, sintering temperatures over $1100^{\circ} \mathrm{C}$ are typically required to homogenize the alloying elements in hydrogen-free systems. ${ }^{2}$ Aluminum and vanadium are both substitutional alloying elements and, therefore, diffuse by a vacancy mechanism. ${ }^{48}$ Therefore, it is likely that the presence of hydrogen improves homogenization of the alloying elements in addition to improving densification during sintering via the same mechanism.

The diffusion of hydrogen is also an important consideration in HSPT studies, as it serves to both densify the material and refine the microstructure. A gradient with coarser grains near the center of a sample is produced if insufficient $\mathrm{H}_{2}$ partial pressures are used during the sintering and phase transformation steps. This produces an insufficient hydrogen concentration to refine the microstructure near the center of the sample during the phase transformation step. Recently, it has been found that a similar gradient is produced when using higher dehydrogenation temperatures. ${ }^{31}$ This is the result of a hydrogen concentration gradient that is produced during dehydrogenation, and due to the fact that hydrogen is a strong $\beta$ stabilizer. If certain temperatures are reached before sufficient hydrogen is removed, the regions of higher hydrogen concentration near the center completely transform to $\beta$, which coarsens the microstructure.

As mentioned above, detailed analyses of the zirconium and hafnium samples were beyond the scope of this study. However, all three metals form similar eutectoid phase diagrams with hydrogen. Additionally, the sintering temperature was well above the eutectoid temperature (i.e., the temperature at which the hydride phase decomposes) for all three metals, which is reported to be $\sim 300^{\circ} \mathrm{C}$ for $\mathrm{Ti}-\mathrm{H}^{49} \sim 550^{\circ} \mathrm{C}$ for $\mathrm{Zr}-\mathrm{H},{ }^{50}$ and $\sim 700^{\circ} \mathrm{C}$ for $\mathrm{Hf}-$ H. ${ }^{51,52}$ Finally, all three systems have significant hydrogen solubility in the $\beta$ phase at the sintering temperature. ${ }^{49-52}$ Therefore, it stands to reason that all three metals experienced improved densification due to the same hydrogen-induced vacancy mechanism.

The shape, size, and distribution of pores are well known to have a significant effect on the mechanical performance of metals. ${ }^{53}$ For the ultrafine-grained HSPT microstructure shown in Fig. 4c and d, the threshold size for pores to dominate fatigue failure has been previously determined to be $43 \mu \mathrm{m}$ for a surface defect and $73 \mu \mathrm{m}$ for an internal pore..$^{54,55}$ Much larger pores are necessary to significantly affect tensile testing, as the stress intensity required to cause fracture under a static load is an order of magnitude greater than that required to 
propagate a fatigue crack. ${ }^{56}$ Large "rogue" pores have been found in press-and-sinter HSPT Ti-6Al$4 \mathrm{~V}$, which obviously affect the mechanical performance. ${ }^{54,57}$ Such pores are also an important concern for powder-cast Ti-6Al-4V. However, if rogue pores can be prevented through careful processing, the densification that results from hydrogen sintering is sufficient to achieve excellent mechanical performance.

It should be mentioned that many non-beam AM technologies, such as binder jetting, produce nonuniform pore distributions. For example, these processes can result in a layering effect in the green part, even when spherical powders with excellent flow behavior are used. ${ }^{58}$ As such, this layering effect may alter the pore distribution from that seen in powder-cast parts sintered from tapped powder. Regardless, the enhanced densification during powder casting should translate to AM green parts, thereby improving the performance over vacuum or inert gas sintering. Furthermore, researchers are continually developing technologies to improve the uniformity of their powder beds, such as incorporation of ultrasonic vibratory hoppers to improve powder flow and spread. ${ }^{59}$

\section{CONCLUSION}

In a typical powder metallurgy (PM) or additive manufacturing (AM) process, achieving near-full density from metal powders requires compaction either before or after sintering, the use of spherical powders with engineered particle size distributions and excellent packing behavior, or infiltration after sintering. In this paper, it has been found that hydrogen has a strong enough effect on the solidstate sintering kinetics of several metals to achieve near-theoretical density from low-cost, non-spherical powders, without requiring compaction or infiltration. The authors have named this process "powder casting" due to its similarities to melt casting of metals. However, these findings could hold particular interest for metal AM technologies that produce green parts for subsequent sintering, such as binder jetting, extrusion AM, and ordered powder lithography. Powder casting was used to produce bulk Ti-6Al-4V, $\mathrm{Zr}$, and Hf samples from loose powders at their tap densities. All the samples were sintered using a slight variation of the hydrogen sintering and phase transformation (HSPT) process.

The sintered Ti-6Al-4V condition achieved a relative density (>99\%), average pore size $(8.5 \mu \mathrm{m})$, and pore size distribution consistent with previously reported press-and-sinter HSPT Ti-6Al$4 \mathrm{~V}$ studies. Additionally, the Ti-6Al-4V samples exhibited good tensile properties. Unfortunately, these samples were unintentionally overheated during the dehydrogenation step, which produced a relatively coarse microstructure. As such, the measured strength of this material was significantly lower than that observed in previous HSPT studies.

Due to material and resource limitations, the $\mathrm{Zr}$ and Hf samples were only analyzed for their densities, which were $95.7 \%$ and $94.0 \%$, respectively. These values are lower than that achieved with Ti-6Al-4V, owing to the fact that they have higher melting points and were sintered at the same temperature. Regardless, these materials reached the final stage of sintering ( $>92 \%$ relative density), despite the low initial densities and low homologous sintering temperatures.

\section{ACKNOWLEDGEMENTS}

The authors wish to thank Eric Lam and Griffin Turner of Texas A\&M University for their help in acquiring data during this study.

\section{REFERENCES}

1. O.M. Ivasishin, D.G. Savvakin, F. Froes, V.C. Mokson, and K.A. Bondareva, Powder Metall. Met. Ceram. 41, 382 (2002).

2. Z.Z. Fang, J.D. Paramore, P. Sun, K.S.R. Chandran, Y. Zhang, Y. Xia, F. Cao, M. Koopman, and M. Free, Int. Mater. Rev. 63, 407 (2018).

3. O. Ivasishin and V. Moxson, in Titan. Powder Metall., edited by M. Qian and F.H. (Sam) Froes, 1st ed. (Oxford: Butterworth-Heinemann, 2015), pp. 117-148.

4. J. D. Paramore, Z. Z. Fang, and P. Sun, in Titan. Powder Metall., edited by M. Qian and F.H. (Sam) Froes, 1st ed. (Oxford: Butterworth-Heinemann, 2015), pp. 163-182.

5. F.H. Froes, O.N. Senkov, and J.I. Qazi, Int. Mater. Rev. 49, 227 (2004).

6. J. Greenspan, F. Rizzitano, and E. Scala, Metal Matrix Composites by Decomposition Sintering of Titanium Hydride (Watertown: Army Materials and Mechanics Research Center, 1970).

7. K. Obara, Y. Nishino, and S. Matsumoto, U.S. Patent 3,950,166 (1976).

8. J. Greenspan, F. Rizzitano, and E. Scala, in Titanium, Sci. Technol. Proc. Second Int. Conf. (1973), pp. 365-379.

9. J.M. Oh, J.G. Koo, and J.W. Lim, Met. Mater. Int. 24, 1303 (2018).

10. J.M. Oh, J.G. Koo, and J.W. Lim, Powder Technol. 330, 27 (2018).

11. K.S. Senkevich, Metall. Mater. Trans. A 49, 2990 (2018)

12. P. Sun, Z.Z. Fang, M. Koopman, J. Paramore, K.S.R. Chandran, R. Yang, and J. Lu, Acta Mater. 84, 29 (2015).

13. P. Sun, Z.Z. Fang, M. Koopman, Y. Xia, J. Paramore, K.S. Ravi Chandran, Y. Ren, and J. Lu, Metall. Mater. Trans. A 46, 5546 (2015).

14. J.D. Paramore, Z.Z. Fang, M. Dunstan, P. Sun, and B.G. Butler, Sci. Rep. 7, 41444 (2017).

15. M. Eisenmann, R. Morgan, P.F. Group, and P. Plc, in Powder Metall. (Metals Park, OH: ASM International, 2015), pp. 799-805.

16. R.M. German, Sintering Theory and Practice (New York: Wiley, 1996).

17. M. Ziaee and N.B. Crane, Addit. Manuf. 28, 781 (2019).

18. G. Wu, N.A. Langrana, R. Sadanji, and S. Danforth, Mater. Des. 23, 97 (2002).

19. M. J. Holcomb and I.J. Holcomb Jr., U.S. Patent 2019/ 0240724 A1 (2019).

20. C.G. McCracken, D.P. Barbis, and R.C. Deeter, Powder Metall. 54, 180 (2011).

21. ASTM, B527-93: Standard Test Method for Determination of Tap Density of Metallic Powders and Compounds (West Conshohocken, PA: ASTM, 1993).

22. ASTM, B962-17: Standard Test Methods for Density of Compacted or Sintered Powder Metallurgy (PM) Products 
Using Archimedes' Principle (West Conshohocken, PA: ASTM 2017)

23. C.A. Schneider, W.S. Rasband, and K.W. Eliceiri, Nat. Methods 9, 671 (2012).

24. ASTM, E8/E8M-11: Standard Test Methods for Tension Testing of Metallic Materials (West Conshohocken, PA: ASTM, 2011).

25. B. Wattrisse, A. Chrysochoos, J.M. Muracciole, and M. Némoz-Gaillard, Exp. Mech. 41, 29 (2001).

26. P. Sun, Powder Metallurgy Titanium by the Hydrogen Sintering and Phase Transformation (HSPT) Process, Ph.D. Dissertation, University of Utah, 2015.

27. J.D. Paramore, Z.Z. Fang, P. Sun, M. Koopman, K.S.R. Chandran, and M. Dunstan, Scr. Mater. 107, 103 (2015).

28. J. D. Paramore, Relationship Between Processing, Structure, and Properties of Titanium Alloys Produced by Hydrogen Sintering and Phase Transformation (HSPT), Ph.D. Dissertation, University of Utah, 2015

29. F. Cao, K.S.R. Chandran, and P. Kumar, Scr. Mater. 130, 22 (2017).

30. Z.Z. Fang, P. Sun, and H. Wang, Adv. Eng. Mater. 14, 383 (2012).

31. M.K. Dunstan, J.D. Paramore, Z.Z. Fang, and P. Sun, $M a-$ ter. Sci. Eng., A 764, 138244 (2019).

32. F.A.L. Dullien, Porous Media, 2nd ed. (Amsterdam: Elsevier, 1992).

33. ASTM, B348-10: Standard Specification for Titanium and Titanium Alloy Bars and Billets (West Conshohocken, PA: ASTM, 2010)

34. U. Zwicker and H.W. Schleicher, U.S. Patent 2,892,742 (1959).

35. W. Kerr, Metall. Trans. A 16A, 1077 (1985).

36. Y. Mishin and C. Herzig, Acta Mater. 48, 589 (2000).

37. A.A. Ilyin, I.S. Polkin, A.M. Manonov, and V.K. Nosov, in Titan.'95 Sci. Technol. Proc. Eighth World Conf. Titan. (Birmingham, UK, 1995), pp. 2462-2469.

38. X.L. Han, Q. Wang, D.L. Sun, and H.X. Zhang, Scr. Mater. 56, 77 (2007)

39. R. Laptev, A. Lider, Y. Bordulev, V. Kudiiarov, and G. Garanin, J. Alloys Compd. 645, S193 (2015).
40. Y.I. Archakov, A.M. Dobrotvorskii, V.I. Pokhmurs'kyi, and V.V. Fedorov, Mater. Sci. 31, 477 (1996).

41. Y. Wang, D. Connétable, and D. Tanguy, Phys. Rev. B 91, 1 (2015).

42. C. Yexin, Rare Met. Mater. Eng. 44, 553 (2015).

43. R.J. Wasilewski and G.L. Kehl, Metallurgia 50, 225 (1954).

44. H. Okamoto, J. Phase Equilibria Diffus. 32, 174 (2011).

45. H. Wang, M. Lefler, Z.Z. Fang, T. Lei, S. Fang, J. Zhang, and Q. Zhao, Key Eng. Mater. 436, 157 (2010).

46. H. Okamoto, J. Phase Equilibria Diffus. 33, 491 (2012).

47. O.M. Ivasishin, D. Eylon, V.I. Bondarchuk, and D.G. Savvakin, Defect Diffus. Forum 277, 177 (2008).

48. G. Lütjering and J.C. Williams, Titanium, 2nd ed. (Berlin: Springer, 2007).

49. K. Wang, X. Kong, J. Du, C. Li, Z. Li, and Z. Wu, Calphad 34,317 (2010).

50. D. Setoyama and S. Yamanaka, J. Alloys Compd. 370, 144 (2004).

51. M. Tada, J. Mater. Sci. 25, 2934 (1990).

52. H. Okamoto, J. Phase Equilibria 13, 120 (1991).

53. A.R. Boccaccini, J. Mater. Sci. Lett. 17, 1273 (1998).

54. M.K. Dunstan, J.D. Paramore, and Z.Z. Fang, Int. J. Fatigue 116, 584 (2018).

55. M.K. Dunstan, J.D. Paramore, Z.Z. Fang, J.P. Ligda, and B.G. Butler, Int. J. Fatigue 131, 105355 (2020).

56. R. Boyer, G. Welsch, and E.W. Collings, Materials Properties Handbook-Titanium Alloys (ASM International: Metals Park, OH, 1994).

57. P. Kumar, K.S. Ravi Chandran, F. Cao, M. Koopman, and Z.Z. Fang, Metall. Mater. Trans. A 47, 2150 (2016).

58. A. Mostafaei, P. Rodriguez De Vecchis, I. Nettleship, and M. Chmielus, Mater. Des. 162, 375 (2019).

59. A.S. Dugan, J.J. Bolt, and A.P. Klein, U.S. Patent 9,486,962 B1 (2016).

Publisher's Note Springer Nature remains neutral with regard to jurisdictional claims in published maps and institutional affiliations. 